\title{
New Pragmatic Approach to Learning from Research Practices to Teaching Methodologies
}

\author{
Joseph Kouneiher, Cecile Barbachoux \\ Sciences and Technologies Department - ESPE, Cote d'Azur University, Nice, France \\ Email address: \\ Joseph.kouneihr@unice.fr (J. Kouneiher), cecile.barbachoux@unice.fr (C. Barbachoux) \\ To cite this article: \\ Joseph Kouneiher, Cecile Barbachoux. New Pragmatic Approach to Learning from Research Practices to Teaching Methodologies. \\ International Journal of Education, Culture and Society. Vol. 2, No. 6, 2017, pp. 184-189. doi: 10.11648/j.ijecs.20170206.14
}

Received: March 4, 2017; Accepted: March 24, 2017; Published: December 19, 2017

\begin{abstract}
An essential point of the learning and teaching environment today, is the need to pioneer a new approaches which go beyond some "standard" theorizations of pedagogy. We know by experiences that the most successful solutions should not only engage the students and the teachers but some aspect of those approaches should build on the transformative potential of a digital age, as well as emerging insights into human behavior and the human brain. We must seek to set a standard for innovation in pedagogy and commit to its advance. In this paper we review some existing approaches to learning and we describe a new scientific pragmatic approach. This approach based on the real daily practice of scientific researchers (in Mathematics and Physics and not just a theoretical recipe) gives a new insights to learning methods and promotes the creative side of learning.
\end{abstract}

Keywords: Learning Methdos, Research Methods, Educational Research, Pragmatic Approach, Creative Approach of Learning, Context and Knowledges, Process Oriented Guided Inquiry

\section{Theorizing the Pedagogy}

Current educational programs is permeate by three themes: First is the need to equip youth with the necessary tools to succeed in the new millennium, this means knowing how to access content knowledge efficiently and effectively and to acquire inquiry/problemsolving skills that are meaningful, adaptable, and integrative. Second is the importance of developing creative, collaborative, communicative, and innovative learners who are culturally sensitive, globally aware, and who behave in ethically responsible ways ${ }^{1}$. And third is the need for developing digital literacy to keep pace with the exponentially burgeoning digital world that offers vast promise, but at the same time demands a critical stance to ensure that these tools is used responsibly. In the same talking, technology is playing a critical role in how curricula are being developed and implemented through the creation of

1 The main aim of a formal education is to accomplish and produce individuals who can think and judge for themselves; and to develop a much greater understanding and appreciation of their own potential and most of all identify that of their fellow human beings; and finally can play an effective part in social, economical and political processes. the STEM (science, technology, engineering, and mathematics) curricula to prepare students for lifelong learning and the demands of the future ${ }^{2}$.

The education literature at the moment have always focused in knowledge building to realize those tasks ${ }^{3}$. Indeed, recently pedagogies ${ }^{4}$ are being rethought as learning how to learn becomes paramount in inquiry learning and problem solving. An example is the trend towards the flipped classroom where fact learning is relegated to independent work on the part of the learners and frequently accessed electronically, the lecture-style of transmission learning is eliminated, and classrooms become hives of activity, exploration, application, discussion, reflection, and

2 Of course we can imagine the possibility of expanding this acronym to include language, visual and performing if we truly wish to embrace creativity and innovation in all its forms.

3 This is intimately linked with the question: can the practice of education be the object of a science?

4 Many currents in philosophy of education, for example Marxists, pragmatists, positivists, and many others debated not only the character of science but also its relations to social and cultural matrices. Much of this work took its shape from a pedagogical goal: to inculcate citizens with the scientific attitude that most disputants, despite their theoretical differences, agreed was the cultural prerequisite for democracy in an industrial age. 
collaboration. There is no doubt that technology has helped to facilitate this, and to widen the possibilities for teaching learning and connection. At the same time it has created new problems around issues of accessibility, safety, and accountability.

\subsection{Status Report}

Actually, we can trace back the main causes of the crisis in educational research today, first to the apartheid that divides positivist and constructivist researchers with positivists believing in an objective reality and constructivists ${ }^{5}$ arguing that reality is a social construction. Second, to the view that the positivist paradigm has come to dominate research to the detriment of more open, pluralistic ${ }^{6}$ and critically reflective approaches ${ }^{7}$. Third, it is linked with the argument that in an increasingly complex and uncertain world, researchers have retreated to a reactionary position in order to shore up the dominant paradigm. Fourth, is based on the fact that governments, especially, are demanding more evidencebased research in order to provide urgent solutions to educational problems [5]. What the Government appears to want are large scale, interdisciplinary, quantitative studies to produce the cumulative body of knowledge that would benefit educational practice. This model represents an ideology of technique of engineering type and an overextension of the scientific paradigm into the judgement-based and reflective world of education. This raise the question of its fallibility, its temporary validity, and its provisional authority. From this point of view, the educational research can only offer a modest practical contribution.

\subsection{Some Known Approaches}

In this section, without getting in much detail, we present the approaches that are currently in vogue [6].

\section{- Pedagogy of Reality}

This approach focuses on teachers gaining an understanding of student realities, and then using this information as the starting point for instruction. The fundamental premise that students are the experts on how to teach, and students are the experts on content. The essential point in this approach is the fact that for teaching and learning to happen, there has to be an exchange of expertise between students and teacher.

\section{- Process Oriented Guided Inquiry}

Here the learning strategy has both a constructivist and social component. Essentially, it focuses on using the real life experiences of the learner to create knowledge and considers how students relates to the environment where they are taught. The main role of the teachers is as «teachers guide

5 Constructivists blurring the distinction between researcher and the researched, so that research findings are created rather than discovered.

6 From this point of view, the university needs to embrace wider criteria of research in order to advance its role of creating public understanding and enlightenment.

7 This has been achieved by research which is driven by performative and economic agendas and the fact that governments favour an objectivist, outcomesoriented approach the inquiry» by asking questions that will eventually move the students towards thinking deeply and drawing more complex conclusions. This approach increased mastery of content in the science classes where it is mostly used.

\section{- Project Approach}

In the project-based learning we focus essentially on having students engage in explorations of real-world problems and challenges. They develop their content knowledge and solutions to problems through these explorations, This approach provides teachers and students with opportunities to be creative. Students in this approach can engage in a project, and learn all subjects as they complete their project. Notice that in this process, the teacher develops ways to connect the subject to the project, and the students in this case look to the teacher for content knowledge to complete their project.

\section{- Flipped Classroom Approach}

This approach «à la mode» involves a process where the typical lecture that happens in the classroom occurs at home. For instance, students watch lectures on video, and then engage at school in the exercises they would traditionally have for homework. In this process, students create, collaborate and learn at their own pace, and apply what they have learned at home in the classroom.

\section{Toward a New Pragmatism}

The word Pragmatism is of Greek origin (pragma, which means work, matos $=$ deed, from prassein $=$ to do). So, Pragmatism means action, from which the words practical and practice have come. In this regard, pragmatism has been conceived as philosophy of workability which encourages us to seek out processes, and to do things which work best to help us achieve desirable ends [10].

From social point of view, It is the product of practical experiences of life. Indeed, Pragmatists hold that everything should be tested on the touchstone of experience, and that an idea is true if it works; if it can be verified, validated and corroborated, otherwise it is abandoned [1]. This is because knowledge claims are tentative and subject to revision. Hence, pragmatists are more concerned with the process of constructing, using and testing knowledge than with transmitting bodies of alleged permanent truths [11].

It does not believe in fixed and eternal values. It is dynamic and ever-changing. It is a revolt against Absolutism. Reality is still in the making. It is never complete. The pragmatist lays down standards which are attainable. They face problems and try to solve them from practical point of view. Pragmatists view life as it is, while idealists view life as it should be. The central theme of pragmatism is activity. Pragmatism accepts everything that has practical consequences. Even mystical experiences are accepted if they have practical results. Unlike idealists they believe that philosophy emerges out of educational practices while the idealists say that education is the dynamic side of philosophy. Teaching-learning process is a social and bi-polar process. Learning takes place as an interaction between the teacher 
and the taught. While idealism gives first place to the teacher, pragmatism gives the first place to the taught. Similarly, between thought and action, they give first place to action. The pragmatists decry verbalism and encourage action.

According to pragmatism the theory and practice of education is based on two main principles, viz:

(i) Education should have a social function, and

(ii) Education should provide real-life experience to the child.

Pragmatism does not lay down any aims of education in advance. The only aim of education, according to pragmatism, is to enable the child to create values in his life.

In the classroom, adopting pragmatic approach implies giving the learner a great deal of freedom of choice in seeking out the experiential (learning) situations that would be most meaningful to him. In other words, the learner must be actively involved in the teaching-learning process, i.e., he should learn by doing because the classroom is a scientific laboratory where ideas are put to test to see if they are capable of verification. In this regard, the teacher plans and arranges the learning experiences, while the learner is given the freedom to work on materials provided in order that he personally experiences the outcome of his actions [10]. Education, for the pragmatists, is an experimental process a method of solving problems that challenge the individual as he interacts with his environment. In the classroom, the teacher should bear in mind that pragmatists hold that a variety of methods be employed as no one method of teaching would adequately cater for the different interests of the learners.

The pragmatist educator aims at the harmonious development of the educand physical, intellectual, social and aesthetic. The aim of education, therefore, is to direct « the impulses, interests, desires and abilities towards the satisfaction of the felt wants of the learner in his environment ». So, education should aim at the development of social efficiency in man. Every child should be an effective member of the society. Education must fulfill his own needs as well as the needs of the society.

The pragmatism commends for abandoning the idea that one can say how things really are, as opposed to how they might best be described in order to meet some particular human need. Pragmatists reject the claim to tell it like it is and accept instead the view that as a man is so he sees, thereby showing that our descriptions of the world whether based on science or constructivism, are partial and, almost irredeemably.

\subsection{The New Scientific Pragmatism Approach}

The new scientific pragmatic approach is motivated in some degree by the fact that the majority of mistakes in ordinary thinking (outside technical matters) are mistakes in perception. Our traditional emphasis on logic does little for perception. If the perception is inadequate no amount of excellence in logic will make up for that defficiency. Perception is a matter of directing attention.

If you are not looking in the right direction it does not matter how clever you are, you will not see what you need to see. From the new approach point of view, the children should be so trained that they may be able to solve their present-day problems efficiency and to adjust themselves to their social environment. They should be creative and effective members of the society. Their outlook should be so dynamic that they can change with the changing situations.

What the new pragmatism ${ }^{8}$ wants to achieve through education is the cultivation of a dynamic, adaptable mind which will be resourceful and enterprising in all situations, the mind which will have powers to create values in an unknown future. Education must foster competence in the children that they may be able to tackle the problems of future life.

So what it means one needs to be pragmatic? Usually, one cannot have too much of a preconception of what problem one aims to solve. One has to be ready to take advantage of opportunities as they arise.

Reluctantly, we had to accept that the problem that we wanted to solve was too diffcult, and to make any progress at all, we had to lower our sights considerably and consider much more limited problems. So, in accepting this and making what progress we could on more limited problems, we could treat more diffcult problems.

Note, that the new world of uncertainty and supercomplexity pushed us to search instead a false certainty ${ }^{9}$ [2]. Research has contented itself with shoring up existing pillars of knowledge and with entrenching existing frames of reference. Instead of reconstructing research, the majority of researchers work to conserve and strengthen the dominant paradigm and only a few embrace uncertainty and attempt to offer a significant reframing of their fields of inquiry. The new pragmatic approach call for plurality ${ }^{10}$ and to move away from primacy. That is, a move away from a closed and, apparently, coherent positivist approach to research towards a much more open and pluralistic view. So, Learning should be conceived more as a journey where the issues raised and the processes undergone contribute to the teachers own personal critical reflection as well as helping to generate «socially useful knowledge ».

This approach, in contrast with other pluralistic approach, still adopt the view that science discovers an actual reality out there, that scientific truth directly corresponds with reality. Indeed, a pragmatists in our sens, could still accept the notion of a single description of the world in the way in which communities of problem-solving scientists converge on a single solution to a given problem.

Nevertheless, we can still argue for an inquiry which leads

8 The real issue here is that the learning of students comes more in line with the research activities of their teachers.

9 The idea is that the researchers in education must reframe both themselves and the research activities they pursue since they can no longer claim to deal in certainties and must console themselves with dealing in uncertainties (tentative responses, possible readings and suggested ideas for action).

10 Putting such activities as poetry, painting, novel-writing, literary criticism and serious journalism on an equal footing with physics and ethics. They are all forms of inquiry which help us cope with the complexities of the world we inhabit 
to descriptions which meet our particular needs. Such descriptions, however, can only be tentative, possible and suggested and can only last until they are overtaken by even more useful re-descriptions. For example, It may be hard for someone who does not work in mathematics or science to fully appreciate the difference between understanding what is true and understanding why it is true. But this difference is an important part of the fascination of physics and mathematics, and we guess all of science. We will say, however, that the difference between what and why depends on the level of understanding one has at a given level of time. One generation may be satisfied with the understanding of why something is true, and the next generation may take a closer look.

\subsection{Pragmatic Approach to Problem Solving}

So new pragmatic approach try to exhibit how methodical and structured we are. So, we are attempt to take a pragmatic approach to problem solving by first identifying the problem, secondly considering various options, and then end with an example:

The best way is to think of an example....so "how do you go about solving a money problem, I.E saving money?

1. You look at the options to solve the problem or issue and come up with number of options

2. You choose one option

3. You evaluate the option you have chosen

Pragmatists see no point in making one form of inquiry any more important or valuable than any other since they are all ways of helping us to cope with aspects of the world. Indeed, for the pragmatists the false dualism which arise in research and learning between positivists (scientists) and constructivists by stressing that they would not privilege any one paradigm or methodology over another ${ }^{11}$. Some pragmatists inclined to see the language and methods of science as just one more vocabulary and one more tool for achieving some of our human purposes. Indeed pragmatism views literature and the arts also as inquiries on the same footing as scientific inquiries and it sees ethics, for example, physics is a way of trying to cope with various bits of the universe; ethics is a matter of coping with other bits.

From our point of view scientific pragmatism is mainly concerned with developing creativity and followed by understanding it. So thinking is a skill you can develop; it is something you can learn. The main idea is that creativity in terms of new ideas and new perceptions is a learnable skill. So pragmatic thinking is about changing concepts and perceptions. For instance, in certain problems it is necessary to shift our attention, to approach the problem from a new perspective in order to solve them. In principle the Pragmatic thinking is mainly concerned with the generation of new perceptions and new ideas. It is in fact a process of changing perceptions; as in the case of changing the way we look at things. Pragmatic thinking is about reasoning that is not

11 They would argue that both science and constructivism offer different sets of tools for investigating the world and different vocabularies for describing it. immediately obvious and about ideas that may not be obtainable by using only traditional step-by-step logical thinking. As illustration, in the traditional argument thinking each side takes a different position and seeks to prove that the other side is wrong ${ }^{12}$.

Pragmatic Thinking offers a practical alternative: it relied on and encourages the co-operation, exploration and innovation. It imply a commun basis: be neutral and objective, consider the pure facts and figures and keep in mind the facts, just the facts ${ }^{13}$. To be effcient a big effort is developed to Identifies information that is missing: what do we have; what do we need; what is missing.

Furthermore, in this approach we can easily legitimizes emotions ${ }^{14}$ and feeling, in contrast of neutral. For instance, the use of a negative judgement faculty can be part of the process of thinking so the logical reasons must be given. In short, to manage the thinking process: first, defines the problems and shapes the questions, second ensures that the rules are observed. The emphasis in education has always been on logical sequential thinking which is by tradition the only proper use of information, to make immediate judgments for example. Instead, the main purpose of pragmatic thinking is to provides a means to restructure patterns. This restructuring of patterns is necessary to make better use of information that is already available. So the pragmatic thinking is the process of discovering the links that unite seemingly disconnected elements. It is a way of mentally taking things apart and putting them together to furnish new insight ${ }^{15}$ for all types of problems.

Remark that the mechanisms underlying insight [14] may well involve a phenomena capable of contributing something to our understanding of the process of learning through encoding and concept identification, problem construction and category selection etc. Taking this fact into consideration we can propose different kind of activities to improve learning:

1) Present a different sort of shapes and ask the students themselves to devise new patterns for illustrating the same thing or devise new shapes. For instance: Using geometrical shapes to illustrate the deliberate search for Non-geometrical shapes and vis versa.

2) Ask students to interpret a situation and give different

12 Argument is relied on the idea that if you remove what is wrong; you will be left with what is right. The reality is that most arguments, and therefore meetings, result in very little constructive output at all.

13 Those facts are divided in two catgories: the first which is supposed checked and proven and the second supposed to be believed and to true.

14 Values and emotions determine the outcome of our thinking. The purpose of thinking is to arrange the world in our minds so that we can apply values and emotion effectively.

15 Insight is the power or act of seeing into a situation; it is also the act or result of apprehending the inner nature of things or of seeing intuitively. Insights may also represent a complex phenomenon involving effort and preparation, failed initial solution attempts, restructuring of the initial problem, and the emergent of an affectively laden solution with the development of the new approach. From this point of view it may be advantageous to explore a definition of the creative event not as an idea that is newer and better but as a shift in perspective or belief that makes new possibilities obvious. This shift in perspective is also known as having insight. 
ways of looking at a picture. The sources of those pictures can be taken from newspapers and magazines to be linked with the events of everyday life.

3) Provide students a stories obtained from newspapers or books used elsewhere in the curriculum, and ask them to generate different points of view of the people involved, or change what is a favorable description to an unfavorable one not by changing the material but by changing the emphasis and looking at it in a different way.

4) Problem solving. Student can be asked to generate alternative ways of stating the problem or alternative approaches to the problem.

\section{Pragmatic Approach, Innovative Technology}

The traditional methods of teaching as well as learning call for drastic changes in the modern age through improvised technology and innovations in curriculum and assessment. The expectations are to have pragmatic and innovative techniques with assumption that the role of school and universities will be for preparing knowledge and developing work skills to cope-up with the challenges of the present millennium.

Learning technology paves the way for more engaging and sometimes personalized learning approaches; where students work collaboratively, test new skills hands-on or virtually, and explore the world beyond the classroom walls.

Nevertheless, creating effective and increasing focus on online global collaboration where contemporary digital tools engage students with others around the world to support curricular objectives and intercultural understanding [7, 8]. In addition, technology provides a means for learners to explore subject matter through the act of creation rather than the consumption of content. For example, mobile technologies encourage students production of media coursework; handson learning experiences support STEM- related pedagogy. So, it is not surprising that the adaptability inherent in various forms of technology can be used to enhance the nuances of differentiated learning and the responses of educators to the special needs of students.

\subsection{Integrated Digital Solutions}

Notice that Integrated Digital Curriculum solutions, for example, content and curricula can be truly born digital rather than born for paper delivery, and they can now be born accessible, too ${ }^{16}[3]$, tie together the necessary architectures, software platforms, and infrastructures that allow users to engage with the content in a variety of ways and pull specific material together for individual students and may even be customized for teachers and parents ${ }^{17}$.

16 Technology enhancements, like the delivery of accessible digital content, 24/7 access of services and systems on mobile devices, support of learning aids like screen readers, all reduce factors that may limit success and impede equitable participation.

17 Together, with embedded digital assessment and analytics capabilities,
As an example of such learning Management systems for middle, and high schools, we can use a new web-based system, creating a new personalized learning environment. Assessments are aligned to curriculum standards and reflective of grade levels and contents. Teachers use webbased systems reporting features to analyze assessment results by curriculum standards and skills to direct instructional planning; and then access and schedule appropriate content into their lesson planners ${ }^{18}$ [16].

Finally, project-based learning, problem-based learning, inquiry-based learning, and similar methods foster more active learning experiences, both inside and outside the classroom. As schools adopt tablets, smartphones, and other devices more readily, educators connect curriculum more easily with real life applications ${ }^{19}$.

\subsection{Experience: Game-Design and STEM Self-Efficacy}

Our idea is to use a program which is a game design intervention to introduce students to game design and social media by putting them in the role of a game designer and developer, offering one approach to mitigating these gaps.

Theoretically, it may be that for some students, creating games about a social issue to which they have a personal connection leads to greater affective identification with the activities themselves, which may in turn cultivate their interests in careers in the $\mathrm{STEM}^{20}$ disciplines.

The game-design program, developed by Seymour Papert and colleagues at the MIT Media Lab, places young learners in the role of game designers who model the behaviors of professionals, such as computer scientists and engineers. The cognitive idea behind is to develop the students STEM related self-efficacy ${ }^{21}$ (see [17]).

Theoretically, it may be that for some students, creating games about social issue to which they have a personal connection leads to greater affective identification with the activities themselves, which may in turn cultivate their interests in careers in the STEM disciplines:

People with high assurance in their capabilities approach difficult tasks as challenges to be mastered rather than as threats to be avoided. Such an eficacious outlook fosters intrinsic interest and deep engrossment in activities. They set themselves challenging goals and maintain strong

Integrated Digital Curriculum Solutions can evaluate student proficiencies and prefidefined goals, update administrators,

18 Technology transform school content material from information published in expensive, proprietary textbooks to assessable, mix-and-match digital learning objects and online information resources. Digital content also transforms teachers from content synthesizers to active, content creators and curators.

19 With the adoption of 3D printing, students can view or print out a fossil or historical monument in $3 \mathrm{D}$; at a more complex level, students can generate theoretical concepts and simulate them in 3 dimensions. Lesson plans aligned to numerous subjects like English, Math, and Science; This 3D systems provide training resources to help teachers to incorporate $3 \mathrm{D}$ printing in their instruction and to understand the learning outcomes.

20 Science, Technology, Engineering, and Mathematics

21 Several studies have concluded that interventions involving successful experiences increase

STEM self-eficacy. 
commitment to them. ([17] p. 11).

This research uses an inductive case study method, drawing on data sources that include classroom observation of student teams in situ, interviews with students, students written reflections, survey responses on student self-eficacy related to STEM, teacher interviews, and students game artifacts. The primary focus of observation is the students attributes of eficacious behavior in the learning environment as the team learns to develop games. Teacher kinterviews addressed student behavior and interactions that demonstrated attvributes related to problem-solving and efficacious behavior.

\section{Conclusion}

The idea of a new approach to teaching and learning centered on students and their needs has become indisputable for education. It is currently essential to build new products and formats in teaching, in such a way that we have seen the birth of a new way of creating knowledge. Technology has become second nature in the daily life of students and they rely on it to manage their lives. In all of these approaches, the most powerful thing to recognize is that they focus explicitly on engaging both the student and the teacher. When teachers are treated like the intelligent professionals that they are, and given the exibility to engage in approaches to teaching and learning, students respond differently, and education is improved [4].

Some philosopher and sociologist had attempted to theorize proper science teaching; other philosophers have written philosophy of education books to intervene in issues of science pedagogy; and yet other philosophers and sociologist have taken part in public debates and courtroom battles about what should and should not be taught in the science classroom. But the most essential is that we must pioneer new approaches to learning and teaching that build on the transformative potential of a digital age, as well as emerging insights into human behavior and the human brain. We must seek to set a standard for innovation in pedagogy and commit to its advance.

Fundamental skills acquired by undergraduate students during their academic, play a crucial role in their career. One such skill is computational thinking (CT), which will help to solve problems algorithmically using computers. Computational thinking will improve their problem solving skills in a non-conventional manner as this leads the student to think in multiple paths to reach the solution. However, it is a challenge in Computing Education to develop student's ability to solve problems in an algorithmic way.

\section{References}

[1] Aggarwal, J. C., Theory and Principles of Education: Philosophical and Sociological Bases of Education. New
Delhi: Vikas Publishing House. (2002).

[2] Barnett, Ronald, Realizing the University in an Age of Supercomplexity. Buckingham: Society for Research into Higher Education \& Open University Press. (2000).

[3] Betsy Beaumon, EdTech and the Promise of Quality Education for All: On the Americans with Disabilities Act at Twenty-Five, Benetech, July 31, (2015).

[4] Biesta, Gert J. J. \& Burbules, Nicholas C. Pragmatism and Educational Research. Authors manuscript, 23 February (2002).

[5] Graham Badleye, The Crisis in Educational Research: a pragmatic approach. European Educational Research Journal, Vol 2, N 2, (2003).

[6] Heyting, Frieda, Lenzen, Dieter \& White, John, Methods in Philosophy of Education. London: Routledge. (2001).

[7] IMS Global, Identifying and Understanding Pragmatic Trends in the Application of Technology to Improve Learning, 2015 Learning impact report (2015).

[8] Johnson, L., Adams Becker, S., Estrada, V., and Freeman, A. NMC Horizon Report: 2015 K-12 Edition. Austin, Texas: The New Media Consortium. 10. (2015).

[9] Lin, Hsiu Fen, A review on the pragmatic approaches in educating and learning creativity, International Journal of Research Studies in Educational Technology, Vol 1 N 1, 1324, April (2012).

[10] Nwafor, N. H. A. The Fulcrum of Philosophy of Education (3rd Edition). Port Harcourt: Sambis Publications. (2013).

[11] Ornstein, A. C. and Levine, D. U., Foundations of Education. Wadswork: CENGAGE Learning. (2008).

[12] Pring, Richard, The Virtues and Vices of an Educational Researcher, in Mike McNamee \& David Bridges (Eds) The Ethics of Educational Research, pp. 111-127. Oxford: Blackwell. (2002).

[13] Rorty, Richard, A Pragmatist View of Contemporary Analytic Philosophy. (1999a) Richard Rortys home page: http://www.stanford.edu/ rrorty

[14] Sternberg, Robert J., and Davidson, Janet E. The nature of insight. Cambridge, MA: MIT Press, (1995).

[15] Sternberg, Robert J., and Davidson, Janet E. Wisdom, intelligence, and creativity synthesized. New York: Cambridge University Press, (2003).

[16] Tim Clark, The Components of the Digital Age Learning Ecosystem, BYOT Network. and Emerging and Future Trends in K-12 Education, Hanover Research, 9. October (2014).

[17] Albert Bandura, Self-efficacy: Toward a unifying theory of behavioral change, Psychological Review, 84: 2, 191215, (1977).

[18] Daniel A. Luzzo \& al, Effects of self-efficacy-enhancing interventions on the math/science self-efficacy and career interests, goals, and actions of career undecided college students, Journal of Counseling Psychology, 46, 233-243, (1999). 